Www.jmscr.igmpublication.org

Impact Factor 5.84

Index Copernicus Value: 83.27

ISSN (e)-2347-176x ISSN (p) 2455-0450

crossref DOI: https://dx.doi.org/10.18535/jmscr/v5i1.156

Journal Of Medical Science And Clinical Research

\title{
Lumen of the Appendix
}

\author{
Author \\ Swayam Jothi Dorai Raj S.
}

Prof \& Head, Department of Anatomy, Shri Sathya Sai Medical College \& Research Institute, Tiruporur Guduvancherry Main Road, Ammapettai Village, Sembakkam Post - 603108. Chengalpet Taluk,

Kancheepuram District. Chennai - India

Email:nagarisujatha@gmail.com

ABSTRACT
The appendix being the common site for inflammation an idea came to the mind that if the lumen is obliterated
whether we can prevent inflammation. With this idea at the back of the mind a study was made in appendices
which showed obliteration of the lumen or a very little lumen. 300 biopsy specimens sent to the pathology
department of ASRM Medical College, SSSMCRI and MGMCRI were made use for the study. 70 specimens
showed obliteration of lumen. The causes were due to the presence of faecolith, due to lymphoid proliferation
and due to fibrous tissue replacing the lumen. Narrowing of the lumen was further classified into total
obliteration which was observed in 18 specimens, slit like lumen in 9 cases and a very small lumen in 43 cases.
The incidence was more in chronic inflammation associated with lymphoid proliferation and in males. The
obliteration of the lumen of appendix was more common in the age group ranging from 20-40 years during
which time the lymphoid tissue is also more due to repeated infections
Keywords: Appendix. Obliteration of lumen, Lymphoid proliferation.

\section{INTRODUCTION}

The appendix being the common site for inflammation whether obliteration of lumen can prevent inflammation. With this idea at the back of the mind the study was undertaken to see the details of the cases which showed obliteration of the lumen or a very little lumen.

\section{MATERIALS \& METHODS}

300 biopsy specimens sent to the pathology department of ASRM Medical College, SSSMCRI and MGMCRI were made use for the study.

\section{OBSERVATIONS}

70 specimens showed narrowing of the lumen which was further classified into a very small lumen in 43 cases (Fig .1) and slit like lumen in 9 cases (Fig. 2) due to lymphoid proliferation. The age incidence of obliteration of lumen was more during 21 to 40 years (Table I) of the total obliteration observed in 18 cases 8 cases (fig 3) were due to a faecolith and in the other 10 (fig 4) there was obliteration due to fibrous tissue, reticular tissue and fat 
Table No - I - Showing age incidence of Obliteration of lumen

\begin{tabular}{|l|c|c|}
\hline S.No & Age & No of cases \\
\hline 1 & $1-10$ & 4 \\
\hline 2 & $11-20$ & 12 \\
\hline 3 & $21-30$ & 27 \\
\hline 4 & $31-40$ & 22 \\
\hline 5 & $41-50$ & 8 \\
\hline 6 & $51-60$ & 2 \\
\hline 7 & $61-70$ & 2 \\
\hline
\end{tabular}

Table No. II - Showing the incidence of obliteration of the lumen was more in chronic inflammation

\begin{tabular}{|l|c|c|}
\hline S.No & Type of inflammation & No of cases \\
\hline 1 & Chronic & 62 cases \\
\hline 2 & Acute & 6 cases \\
\hline 3 & Acute on chronic & 2 cases \\
\hline
\end{tabular}

Table No. III - Showing the sex prevalence was more in males (46 cases) and less in females (24 cases)

\begin{tabular}{|l|l|l|}
\hline S.No & SEX & No. of Cases \\
\hline 1 & Male & 46 cases \\
\hline 2 & Female & 24 cases \\
\hline
\end{tabular}

Table No. IV - Showing the obliteration of the lumen of appendix was more in the shorter specimens whose length was not greater than $6 \mathrm{~cm}$

\begin{tabular}{|l|c|c|}
\hline S.No & Length of the appendix & No of Cases \\
\hline 1 & $2-4 \mathrm{~cm}$ & 23 \\
\hline 2 & $4-6 \mathrm{~cm}$ & 32 \\
\hline 3 & $6-8 \mathrm{~cm}$ & 11 \\
\hline 4 & $8-10 \mathrm{~cm}$ & 4 \\
\hline
\end{tabular}

Fig 1 : Lymphoid hyperplasia causing narrowing of the lumen (small lumen) of the appendix H\&E (4X) L-Lumen, LH-Lymphoid hyperplasia
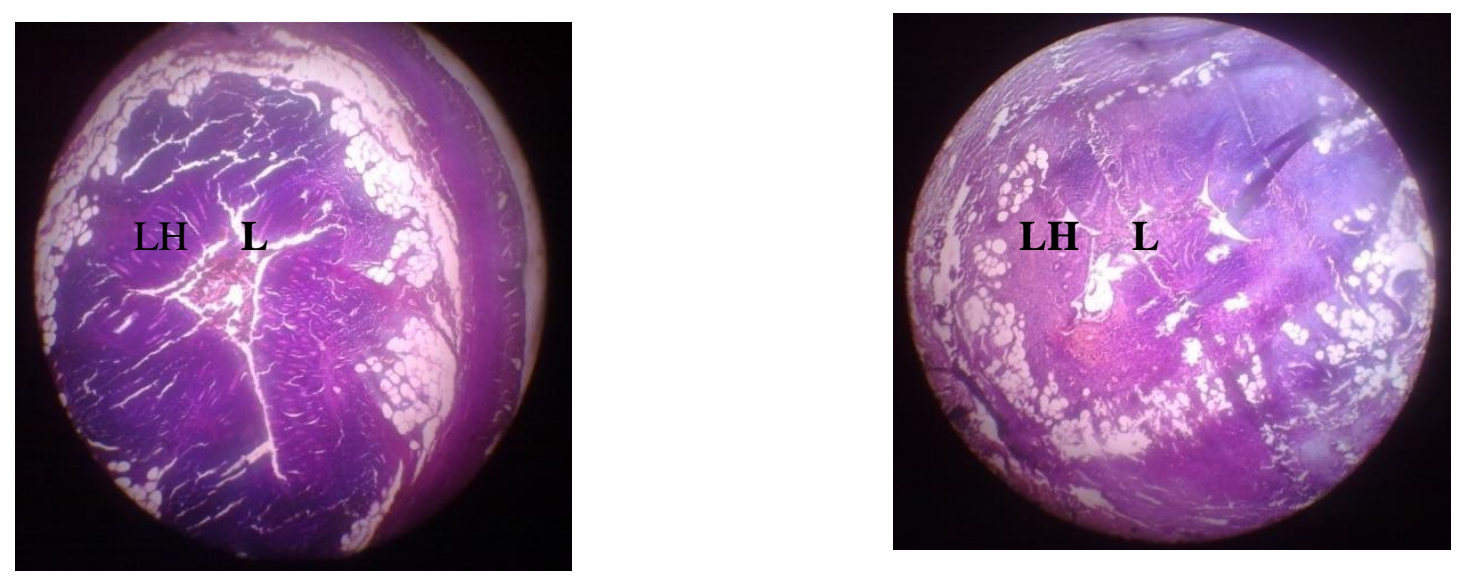


\section{JMSCR Vol||05||Issue||01||Pages 17197-17203||January
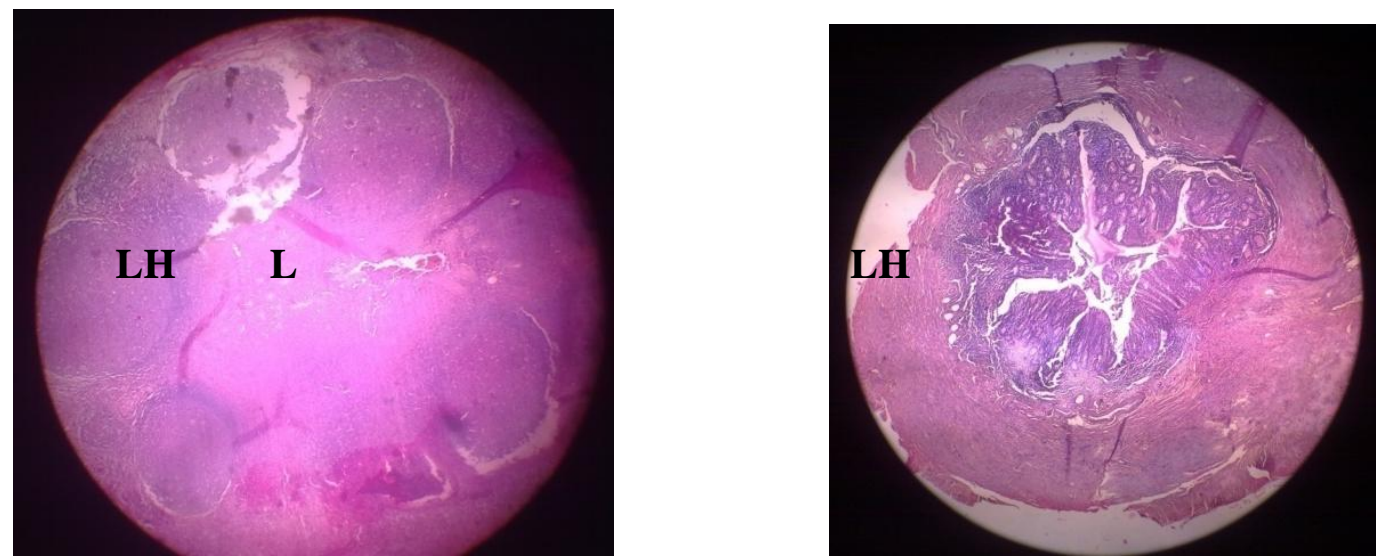

Fig 2 :Lymphoid hyperplasia causing slit like lumen of the appendix H\&E (4X) SL-Slit like lumen ,LH Lymphoid hyperplasia
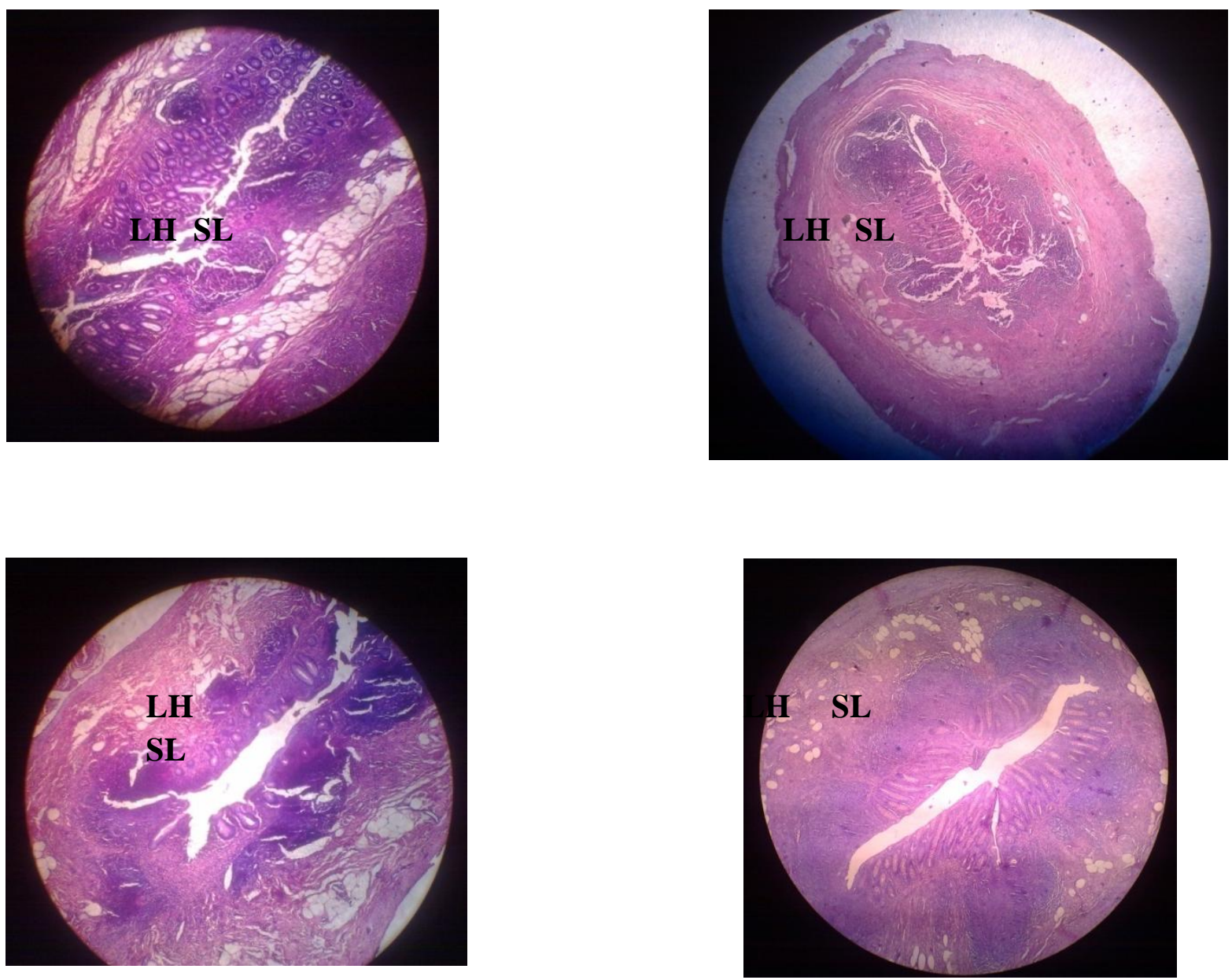


\section{JMSCR Vol||05||Issue||01||Pages 17197-17203||January

Fig 3: Obliteration of lumen of appendix by faecolith H\&E (4X) F- Faecolith in the lumen
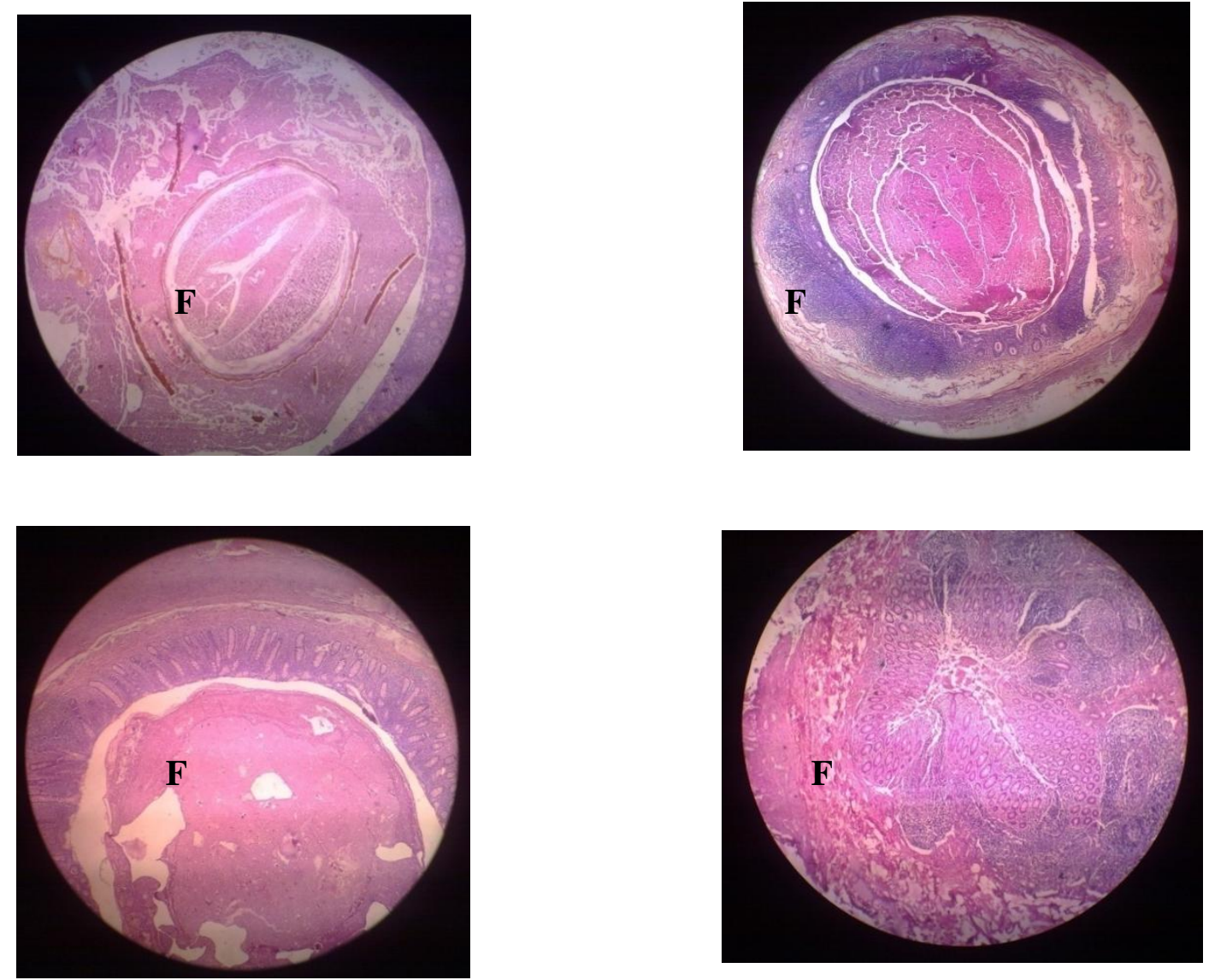

Fig 4: Showing total obliteration of the lumen of the appendix - H\&E (4X) L- Lumen
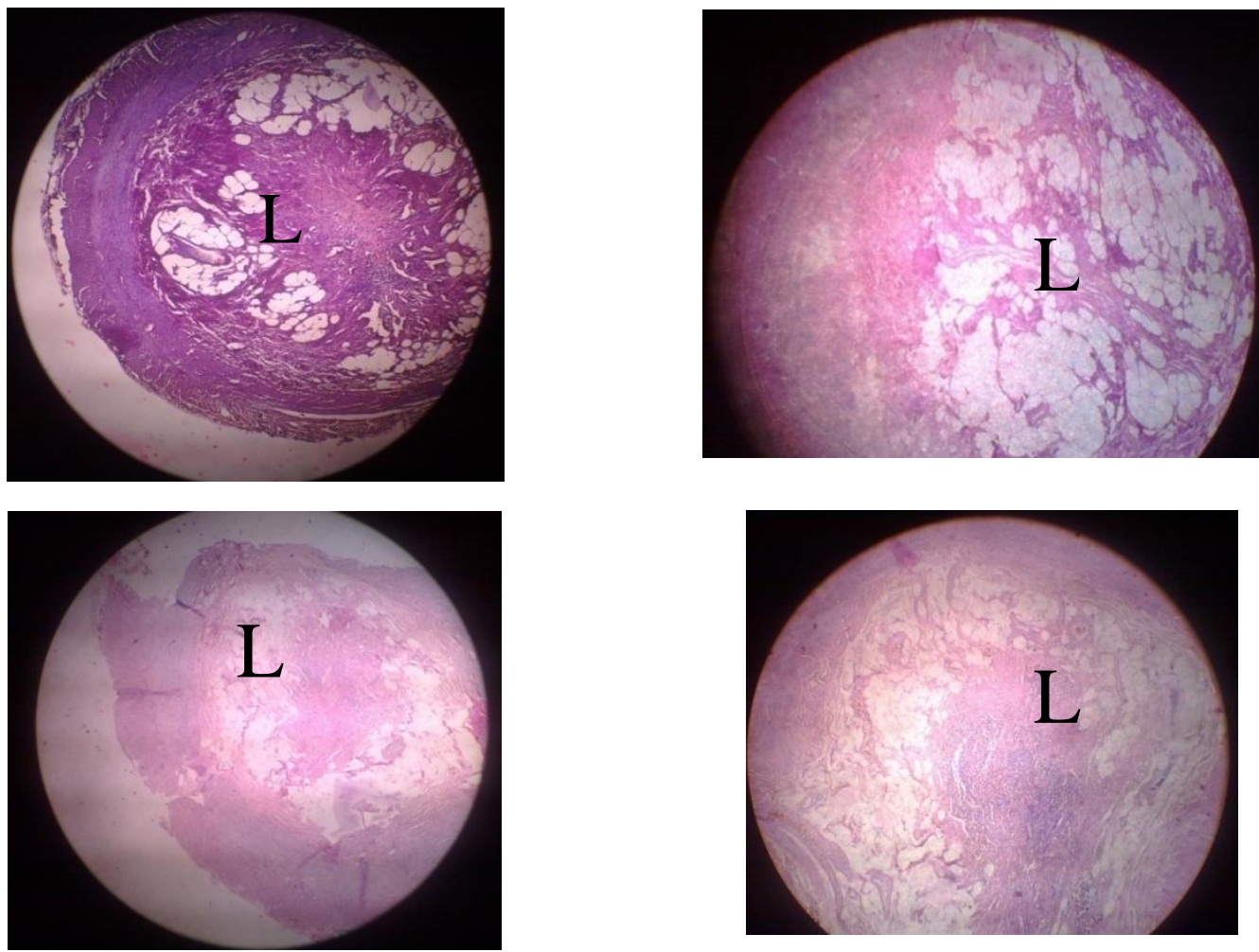
Fig: 5a $\& \mathbf{5 b}$ - For the sake of comparison the lumen of the normal appendix is shown in figure $5 \mathrm{a} \& 5 \mathrm{~b}$
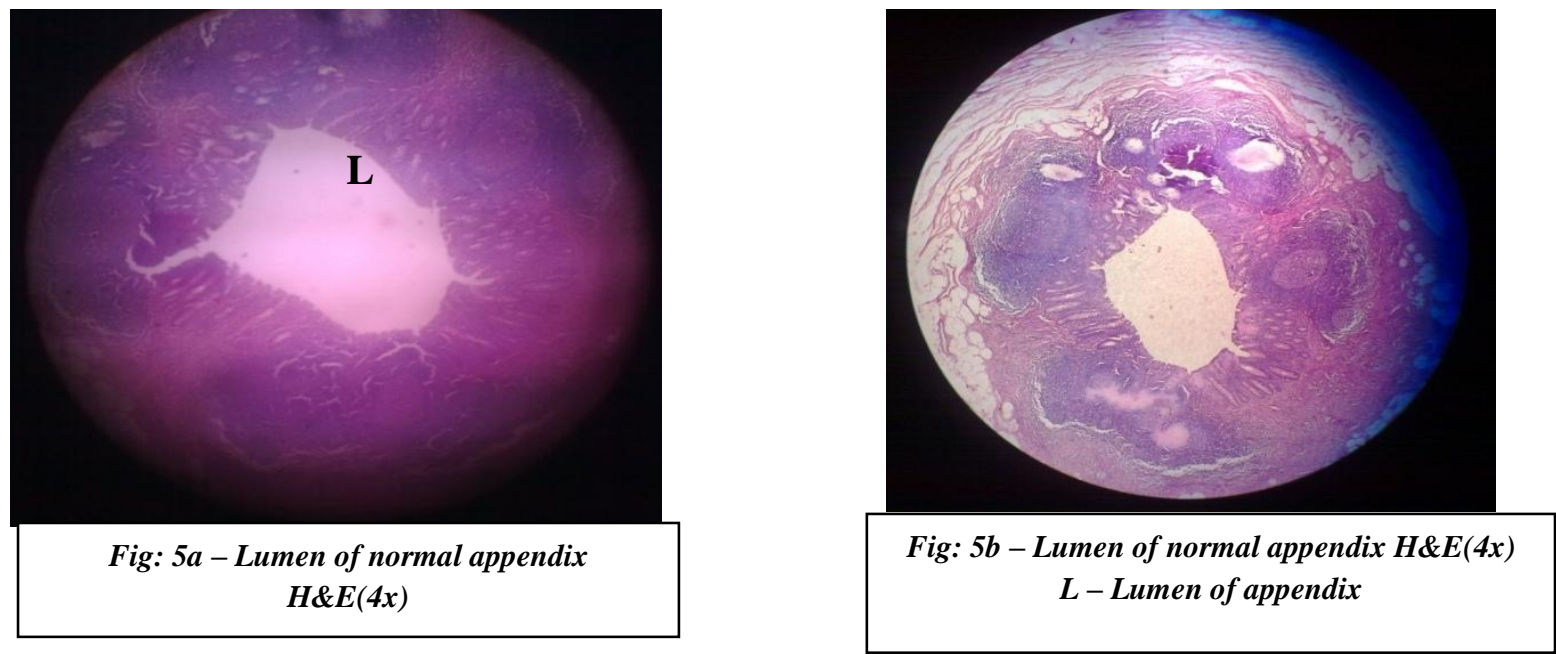

Fig: 6a $\& \mathbf{6 b}$ - In acute inflammation of the appendix the lumen contained edematous fluid (Fig 6a), Mucosa was ulcerated and the lumen contained tissue debris (Fig 6b)

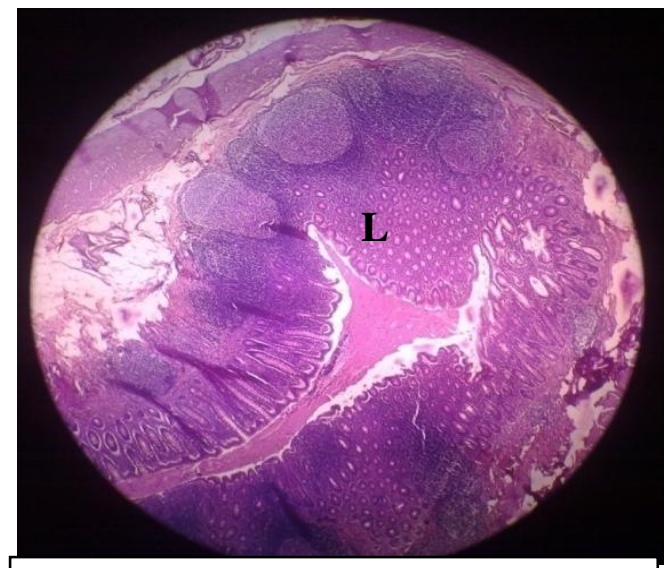

Fig: 6a - Lumen of the appendix containing edematous fluid $\mathrm{H} \& \mathrm{E}(4 \mathrm{x})$ $\mathrm{L}$ - Lumen of appendix

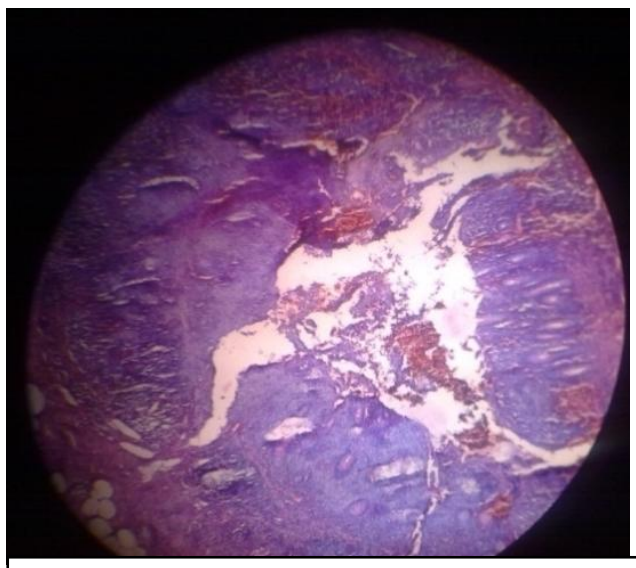

Fig: $6 \mathrm{~b}$ - Lumen of the appendix containing tissue debris $\mathrm{H} \& \mathbf{E}(4 \mathrm{x})$ L - Lumen of appendix

In chronic inflammation where lumen is obliterated special are carried out to demonstrate the presence of collagen (Fig 7a $7 b$ \& 8a 8b) and reticulin (9a \&9b in the lumen)

\section{Van Gieson's picric acid - Acid \\ Fuchsin stain}

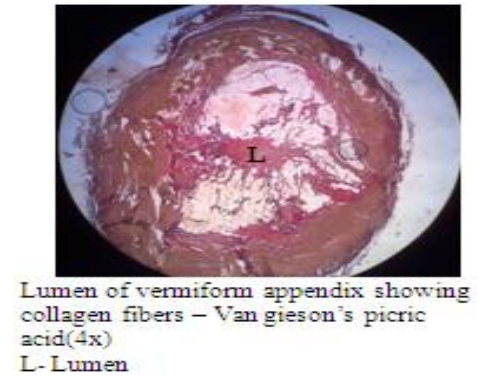

Fig : $7 \mathbf{a}$

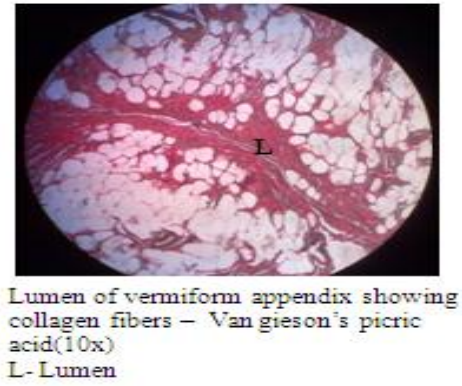

Fig: 7b 
VAN GIESON'S PICRIC ACID-ACID FUCHSIN STAIN

Results

Nuclei..... black.

Collagen.... brilliant red

Muscle and cytoplasm.... yellow

\section{Masson's Trichome Stain}

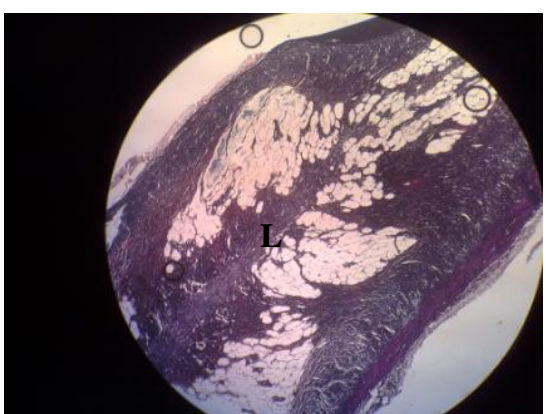

Lumen of vermiform appendix showing collagen fibers -Masson's trichome $\operatorname{stain}(4 \mathrm{x})$

L- Lumen

Fig :8a

MASSON'S TRICHROME STAIN

Results

Nuclei..... black

Cytoplasm, keratin, muscle fibers red

Collagen and Mucus..... Blue.

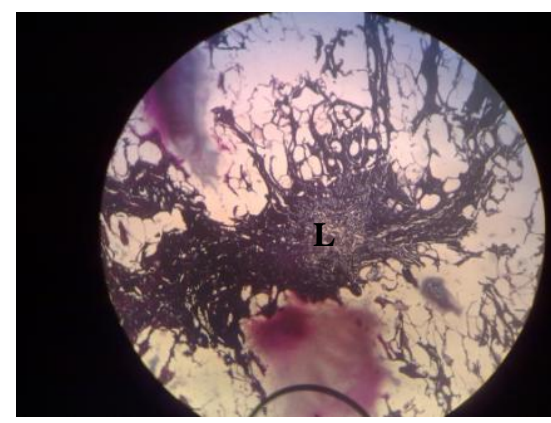

Lumen of vermiform appendix showing collagen fibers - Masson's trichome stain(10x)

L- Lumen

Fig : $8 b$

\section{Gomori’s stain for reticular fibers}

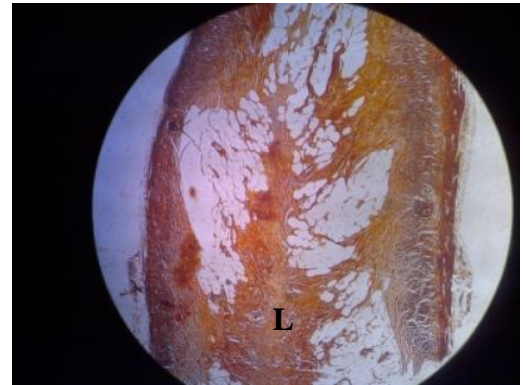

Lumen of vermiform appendix showing reticular fibers - Gomori's stain $(4 \mathrm{x})$ L- Lumen

Fig : 9a

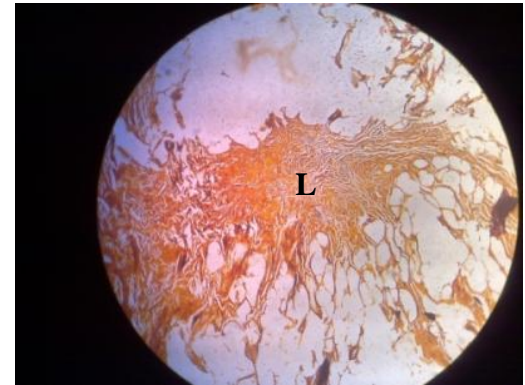

Lumen of vermiform appendix showing reticular fibers - Gomoris stain(10x) L- Lumen

Fig : 9b

GOMORI'S STAIN FOR RETICULAR FIBRES

Results

Reticulin Black 


\section{DISCUSSION}

According to Donald C.Collins(1936) some of the findings derived from his study were as follows: In a series of 1054 specimens 39\% showed varying degrees of lumen obliteration; $61.4 \%$ were males and $38.5 \%$ were females. The present study of 300 specimens showed varying degrees of obliteration in 70 cases $(29.0 \%)$. $66 \%$ were males and $34 \%$ were females. According to Donald C. Collins there were 254 appendices $(24.2 \%)$ less than $6 \mathrm{~cm}$ in length. In this study, the shorter specimens revealed higher percentage of obliteration than those specimens whose length was more than $6 \mathrm{~cm}$.In the present study there were 55 appendices (79\%) less than $6 \mathrm{~cm}$ in length out of 70 appendix specimens. The incidence of obliteration of appendix lumen was more in chronic appendicitis which was also associated with lymphoid proliferation. Maximow (1930), Palmer and Higgins (1993) all agree that fibroblasts may arise from lymphocytes. Mallory (1929) has clearly shown that endothelium also serves in the production of reticulum. This is what has happened in the 10 cases where there was total obliteration of the lumen. These two cellular elements are important factors in the production of obliteration.

\section{CONCLUSION}

The presence of varying number of lymphoid follicles and higher incidence of narrowing in chronic appendicitis favours inflammatory cause for obliteration of lumen. Of the total 18 cases, 8 cases were due to faecolith and the other 10 cases were obliterated by fibrous tissue and fatty infiltration. The age incidence ranged from $20-$ 40 years. This is too early for physiological involution of the lumen of appendix to occur. The obliteration of the lumen of appendix was more common in age group ranging from 20- 40 years during which time the lymphoid proliferation is also more due to repeated infection .If appendix inflammation can be managed conservatively it may lead to total occlusion of lumen of appendix.

\section{REFERENCES}

1. Donald C. Collins (1936)Mechanism and significance of obliteration of the lumen of the vermiform appendix. Annals of surgery, Volume 104, no -2, Pg no - 201 $-2011$.

2. Palmer, Bean M., and Higgins, George M.: A study of the clasmatocytes in the Sacrospinalis Muscle of the Rabit. Am. Jour. Med. Sci., 85,191-196, February, 1993.

3. Mallory, F.B(1929) The principles of pathologic History,PP.486-487, Philadelphia, W.B. Saunders Co.

4. Maximow, Alexander: (1930) A text book of histology, PP. 117 - 150, Philadelphia, W.B. Saunders Co. 